\title{
Simulation Study of Enhanced Oil Recovery by Alkaline Flooding in a Mature Oil Field
}

\author{
Hisham Khaled Ben Mahmud, Yuhashinee Ravichandran \\ Department of Petroleum Engineering, Curtin University Malaysia
}

*Corresponding Author: Hisham Khaled Ben Mahmud, Department of Petroleum Engineering, Curtin University Malaysia

\begin{abstract}
Oil reserves that are available all over the world are explored and commercialised to obtain the fossil fuels it contains. Over the years, due to production, these reserves tend to deplete which leads to a drive to either discover new reserves or come up with much effective method to extract the fossil fuels. Enhanced Oil Recovery (EOR) is carried out to extract the remaining oil that is trapped in it as residual oil and unable to be recovered through primary and secondary recovery mechanism. Alkaline flooding is not only one of the cheapest EOR methods but also one of the most economical method to recover oil as it is easily acquired and is not a very complex substance. The basic concept of alkaline flooding is to inject the alkaline at a certain concentration and rate into the reservoir and this in return reacts with the oil acid to produce soap which is an in-situ surfactant. Due to this reaction, the generated surfactant reduces the interfacial tension (IFT) between the oil and the reservoir rocks which leads to the increase in sweep efficiency. In this study, the objective is to evaluate the effect of altering the alkaline concentration, flow rate and flow period by constructing a simulation model using the reservoir fluid and rock date in Computer Modelling Software (CMG).Sensitivity analysis was performed and the outcomes demonstrated that well pattern and perforation layer has a significant influence on production besides the varying alkaline parameters which also increases production.
\end{abstract}

Keywords: Enhanced oil recovery; EOR, tertiary recovery, alkaline flooding, interfacial tension; IFT, simulation, CMG, STARS

\section{INTRODUCTION}

Oil recovery is divided into three stages depending on the producing life of the reservoir. Primary recovery is the first stage where the natural drive of the reservoir is used for recovery and no external mechanisms are introduced into the reservoir. Primary recovery includes different mechanisms such asexpansion of rock and fluid, solution gas drive, water influx from aquifer, gas cap drive, gravity drainage. Secondary oil recovery is done through the injection of external fluid which is water. This method is done mainly to maintain the pressure but at the same time increase the volumetric sweep efficiency(Sheng, 2011). In an oil field with several wells, when the water is pumped alternatively into wells, it is able to either maintain the reservoir pressure or even increase it(Syed Ata Abbas Naqvi, 2012). Tertiary oil recovery is also known as enhanced oil recovery (EOR) where chemicals, gases and thermal energy are injected into the reservoir.

EOR is defined as any reservoir process that changes the already existing reservoir rock/oil/brine interactions. It is the injection of fluids other than water or brine into the reservoir(Sheng, 2011). The EOR method of alkaline flooding is a process where chemicals such as sodium hydroxide $(\mathrm{NaOH})$, Sodium Orthosilicate $\left(\mathrm{Na}_{4} \mathrm{SiO}_{4}\right)$ or sodium carbonate, $\mathrm{Na}_{2} \mathrm{CO}_{3}$ is injected into the reservoir together with water. The acid in the oil reacts with the alkaline that is injected to form surfactants which then undergoes adsorption that promotes the reduction of interfacial tension (IFT) of oil and water(Abadli, 2012). Besides that, the adsorption also elevates the $\mathrm{pH}$ value of the injected fluid. Consequently, this leads to the mobilisation of the trapped residual oils in the reservoir sand(Syed Ata Abbas Naqvi, 2012). EOR is dependent on several reservoir conditions such as, characteristics of reservoir, depth, salinity and $\mathrm{pH}$. 


\subsection{Statement of Problem, Objective \& Limitations of Study}

This research mainly focuses on the ability to predict the oil recovery potential using alkaline flooding. The study is conducted on how the reservoir factors influence the oil recovery. The well configurations and perforation layers played a part in this study. The effect of changing the alkaline parameters such as the concentration, flow rate and flow duration will also be studied to conclude the amount of oil that can be recovered efficiently. The evaluation of economic valuability of alkaline flooding is also part of the research.

The major limitation during the analysis of this study is the strong aquifer that is active under the reservoir. Although the aquifer functions as a drive mechanism for the reservoir, due to the capacity of the aquifer it leads to an early water cut this requires alkaline to be injected earlier and hence more cost spent on alkaline.

Together with this limitation, certain assumptions were made to simplify justifications in the results and were based on(Keshtkar, Sabeti, \& Mohammadi, 2016), only oil, water and alkaline were the elements taken into consideration, only oil phase and water phase present in the reservoir, zero free gas present in the system, both oil flow and water flow obeys Darcy's Law, the effects of salinity are ignored and no geological complexity and uniform properties of two-dimension system.

\section{MeThodologY}

\subsection{Reservoir Model Description}

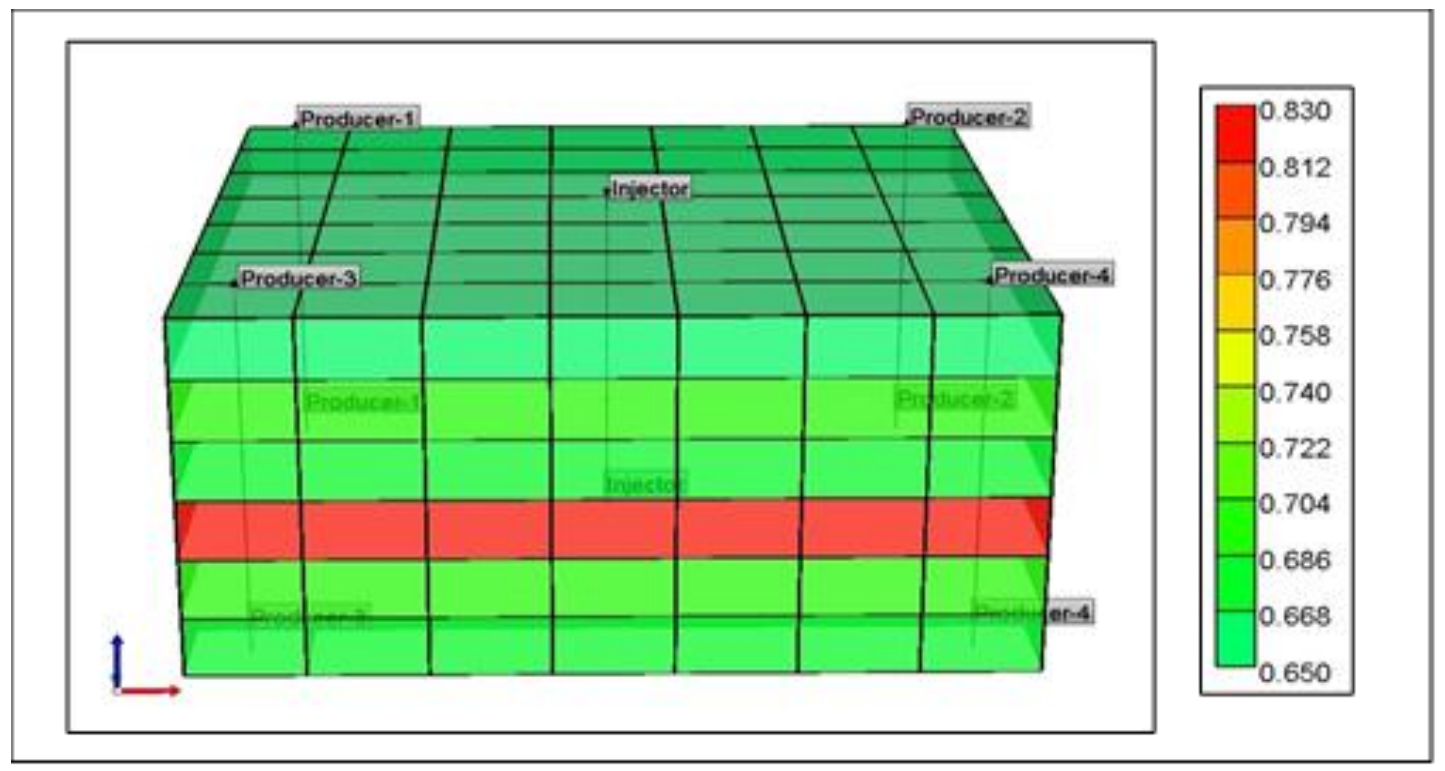

Figure1. Reservoir Box Model

From the reservoir properties data provided in (Appendix A,Table 1), it is concluded that the reservoir has a weak oil expansion and strong aquifer drive. The model was constructed on STARS with the inverted five-spot injection pattern (five producer wells and one injector well) with total grid dimension of $7 \times 7 \times 6$ layers which gives a total of 293 grid blocks, Figure 1.Each grid has the dimensions of $315 \times 315 \times 10 \mathrm{ft}$. For every layer, there are specific property values allocated to it in (Appendix A,Table 2). Data of different water saturations with oil and water relative permeability is also provided for model construction in (Appendix A,Table 3). The reservoir also does not have any fault present and is isothermal.

There simulation was done in three separate stages. The primary flooding, using the reservoirs natural drive, the aquifer was used to obtain the best perforation layers for best oil recovery and reduction of water cut. Secondary method was then carried out, water injection to decide on the best flow rate and injection period. The reservoir pressure was closely monitored for fluctuations. And lastly the tertiary method or EOR, alkaline injection. Alkaline with altered constraints such as concentration, flow rate and flow period was then injected into the reservoir with the decided well pattern and perforation layers. Lastly, the three oil recovery methods werecompared to obtain the configuration with the highest oil recovery. 


\section{RESULTS AND DISCUSSION}

\subsection{Primary Recovery}

Two types of simulation were performed. First, individual layers were perforated and then several layers grouped together. As can be seen in (Appendix A, Figure 1), layer four has the highest amount of oil reserve and as predicted, it recorded the highest recovery factor for individually perforated layer and has a graph shaped almost similar to layers perforated in groups, (Appendix B, Figure 2).In order to decide if it is cost efficient to perforate more layers, reservoir pressure (Appendix B, Figure 3) and oil recovery factors (Appendix B, Figure 4) were compared between layer 4 and layers with the highest oil recovery factor - all layers except layer 6 due to being the closest to the aquifer. Based on the two graphs the pressure drop when more layers are perforated is higher hence the wellbore stability is affected greatly besides that, the recovery factor doesn't show much of a difference, (Appendix B, Figure 4) so perforating only layer four is the best option in order to reduce the production cost.

\subsection{Secondary Recovery}

For water flooding to be simulated, the reservoir initial conditions were first obtained from (Appendix A, Table 3), and graph of oil and water relative permeability against water saturation was plotted, (Appendix C, Figure 5). From this it is concluded that the water has high relative permeability compared to oil so the reservoir is highly oil-wet.

When water injection increases, oil production increases as well but injecting too much water into a reservoir with an already existing strong aquifer is unprofitable due to the early water cut and residual oil being unable to be fully recovered so an injection rate of $2000 \mathrm{bbl} / \mathrm{d}$ is suggested.

Mobility ratio, $\mathrm{M}$ is described as the mobility of fluid displacing by mobility of fluid being displaced (Maheshwari, 2011):

From (Appendix C, Equation 1), the maximum displacement efficiency is obtained when, $\mathrm{M} \leq 1$ (favoured mobility ratio), $\mathrm{M}>1$ (unfavourable) which indicates the motion of displacing fluid, water in this case being greater than displaced fluid, oil. When water can flow past the oil, a phenomenon called 'viscous fingering' occurs. This means water slides through the oil and is produced without containing any residual oil. Even so, mobility ratio, $\mathrm{M}$ can be improved by increasing the viscosity of the displacing fluid, decreasing the effective permeability of the displacing fluid, decreasing the viscosity of the displaced fluid and increasing the effective permeability of the displaced fluid.

Too much water flooding is not advisable as the reservoir has a strong aquifer and alkaline will be incorporated in the EOR later. Water flooding is started off early when the oil production starts declining, 1990. Although there is an increment in the cumulative oil produced, 2,000,000 bbl/d (Appendix C, Figure 6), it does not produce a significant increment due to water being injected into a reservoir with a strong aquifer. So only the water cut increases greatly, (Appendix C, Figure 7). When the flow rate increases, the reservoir has high pressure (Appendix C, Figure8) which leads to an increase in oil sweep efficiency.

\subsection{Tertiary Recovery}

Alkaline flooding is started off as early as a year after water flooding due to the strong aquifer present. as alkaline concentration increases, the oil recovery also increases. This is true up to the concentration of $1.0 \%$ (Pei, Zhang, Ge, Jin, \& Ma, 2013). When alkaline is injected, production rate increases with the increment in alkaline concentration (Appendix D, Figure 9). The total oil produced with alkaline injection gives a maximum amount close to $2,500,000 \mathrm{bbl}$ with an increment of 100, $000 \mathrm{bbl}$ compared to no alkaline being injected.

With a constant alkaline concentration of $1.0 \%$, the flow rates are altered and the oil recovery factor for $2000 \mathrm{bbl} / \mathrm{d}$ is about $70 \%$ which is almost similar to 2500bbl/d (Appendix D, Figure 10). Although $2500 \mathrm{bbl} / \mathrm{d}$ has afaster increment in production, the duration of it is short which leads to a faster drop in reservoir pressure which can lead to wellbore malfunction and ultimately reservoir failure (Appendix D, Figure 11). Also, reduction in contact time and area occurs. The alkaline is not permitted for a thorough reaction with the oil acids and the high rates can result in an earlier breakdown of the water-in-oil emulsion which leads to occurrence of water breakthrough at early stages. So, the number of water-in-oil emulsions is also lower when injection rate exceeds the optimum value(Dong, Ma, \& Liu, 2009). 
The flooding period of alkaline was continuous rather than cyclic as it has a higher recovery amount, (Pei et al., 2013). Alkaline should be injected as early as possible when production starts ceasing for a much economical return (Appendix D, Figure 12). Flow period that is continuous can promote to a much better through emulsification of the water in oil. Heavy oil reservoir means oil has low mobility ratio and hence leads to a poor sweep (Pei et al., 2013). When alkaline is injected continuously, the pressure loss is the greatest (Appendix D, Figure 13), it is validated by (Pei et al., 2013) by concluding that when alkaline is injected continuously, the amount of water-in-oil emulsions produced are greater. Due to this more restrictions are experienced by the water injected and hence the extended plugging effect

\subsection{Comparison of Primary, Secondary and Tertiary Recovery}

\begin{tabular}{|c|c|c|c|}
\hline & $\begin{array}{c}\text { Oil Recovery Factor } \\
(\mathbf{\%})\end{array}$ & $\begin{array}{c}\text { Cumulative Oil } \\
\text { Production (bbl) }\end{array}$ & $\begin{array}{c}\text { Difference in } \\
\text { amount (bbl) }\end{array}$ \\
\hline Primary Recovery & 48 & $1,700,000$ & 0 \\
\hline $\begin{array}{c}\text { Secondary Recovery by } \\
\text { Water Flooding }\end{array}$ & 57 & $2,000,000$ & $+300,000$ \\
\hline EOR by Alkaline Flooding & 64 & $2,300,000$ & $+300,000$ \\
\hline
\end{tabular}

Based on www.alibaba.com the cost of one tonne of $\mathrm{NaOH}$ is USD 600. The density of $\mathrm{NaOH}$ is 1250 $\mathrm{kg} / \mathrm{m} 3$. For the total volume of alkaline that is injected, for 38,000 barrels for the entire 19 years of alkaline flooding the volume of alkaline needed is $6042 \mathrm{~m} 3$. So, it is concluded that roughly 7553 tonne of $\mathrm{NaOH}$ is required for injection which means a sum of USD $4.5 \mathrm{M}$ is needed for alkaline flooding.

\section{CONCLUSION}

1. When the alkaline concentration used is increased, the interfacial tension value decreases. This is true up to a certain point known as the optimum point. Beyond this point, the interfacial tension then increases again.

2. When there is a decrease in interfacial tension, it indicates an increment in oil recovery percentage. The lower the IFT, the greater the recovery of oil and also a larger cumulative oil produced.

3. When the alkaline has a flow rate increment, the recovery is improved but too much of an increment results in reduction of contact between the alkaline and oil this leads to water breakthrough as reaction that occurs is not thorough.

4. When alkaline flow rate is too low, insufficient energy is supplied for interaction and hence gives a low production rate.

5. The increases alkaline flooding period duration has a greater oil recovery. It is preferred to flood alkaline continuously rather than in a cyclic manner and as soon as water flooding ceases producing a profitable amount of oil.

6. Chemical flooding EOR by using the alkaline flooding method has a great potential in the industry. Through this simulation this statement has been proven.

\section{Appendix A:}

Table1. Reservoir Property Data

\begin{tabular}{|c|c|}
\hline Reservoir Properties & Value \\
\hline Water Density & $62.4 \mathrm{Ib} / \mathrm{cuft}$ \\
\hline Oil Density (Stock Tank) & $38.53 \mathrm{Ib} / \mathrm{cuft}$ \\
\hline Water Compressibility & $3.3 \times 10^{-6} \mathrm{psi}^{-1}$ \\
\hline Rock Compressibility & $5 \times 10^{-6} \mathrm{psi}^{-1}$ \\
\hline Water Formation Volume Factor & $1 \mathrm{RB} / \mathrm{STB}$ \\
\hline Water Viscosity & $0.7 \mathrm{cp}$ \\
\hline Oil Viscosity & $1.34 \mathrm{cp}$ \\
\hline Reservoir Temperature & $160{ }^{\circ} \mathrm{F}$ \\
\hline Reservoir Depth & $8150-8465 \mathrm{ft}$ \\
\hline Bubble Point Pressure & $300-500 \mathrm{psi}$ \\
\hline Reservoir Pressure & $3915 \mathrm{psi}$ \\
\hline
\end{tabular}


Simulation Study of Enhanced Oil Recovery by Alkaline Flooding in a Mature Oil Field

\begin{tabular}{|c|c|}
\hline & \\
\hline Oil Formation Volume Factor & $1.18 \mathrm{Brb} / \mathrm{STB}$ \\
\hline Initial Water Saturation & 0.2 \\
\hline Initial Oil Saturation & 0.8 \\
\hline Wellbore Radius & $3000 \mathrm{ft}$ \\
\hline Effective Drainage Radius & $60-205 \mathrm{scf} / \mathrm{bbl}$ \\
\hline GOR (Gas-Oil Ratio) & $8465 \mathrm{ft}$ \\
\hline WOC (Water Oil Contact) & $36.8-38 \mathrm{deg}$ \\
\hline API & $19 \%$ \\
\hline WAS Content & $12-24^{\circ} \mathrm{C}$ \\
\hline Pour Point & $10-30 \mathrm{ft}$ \\
\hline Tar Mat & $1000 \mathrm{bopd}$ \\
\hline Oil Production Rate & $50-81 \%$ \\
\hline Water Cut & $300 \mathrm{ft}$ \\
\hline Maximum Oil Column & $90 \mathrm{ft}$ \\
\hline Average Net Pay & $180000 \mathrm{ppm}$ \\
\hline Water Salinity & $8 \mathrm{~km}$ \\
\hline Average Spacing & $800 \mathrm{psi}$ \\
\hline Average Flowing Well Head Pressure & \\
\hline Weak oil expansion and strong aquifer drive & \\
\hline
\end{tabular}

Table2. Reservoir Layer Property Data

\begin{tabular}{|c|c|c|c|c|c|c|}
\hline & \multicolumn{6}{|c|}{ Layers } \\
\hline Properties & 1 & 2 & 3 & 4 & 5 & 6 \\
\hline Permeability, k (mD) & 17 & 68 & 30 & 286 & 74 & 64 \\
\hline Porosity, $\varphi(\%)$ & 14 & 19 & 16 & 18 & 17 & 16 \\
\hline Net to Gross, NTG & 0.5 & 0.32 & 0.38 & 0.96 & 0.72 & 0.65 \\
\hline Oil Saturation, $S_{0}$ & 65 & 69 & 67 & 83 & 70 & 67 \\
\hline Net Volume $\left(10^{6} \mathrm{~m}^{3}\right)$ & 50 & 1,169 & 2,502 & 3,800 & 5,232 & 1,462 \\
\hline Pore Volume, PV $\left(10^{6} \mathrm{rm}^{3}\right)$ & 7 & 209 & 445 & 692 & 822 & 251 \\
\hline $\begin{array}{l}\text { Hydrocarbon Pore Volume, HCPV oil } \\
\qquad\left(10^{6} \mathrm{rm}^{3}\right)\end{array}$ & 3 & 97 & 187 & 433 & 407 & 68 \\
\hline $\begin{array}{c}\text { Stock Tank Oil Initially in Place, } \\
\text { STOIIP (Mstb) }\end{array}$ & 13 & 516 & 994 & 2,308 & 2,170 & 359 \\
\hline $\begin{array}{c}\text { Average NTG above Oil-Water } \\
\text { Contact, OWC }\end{array}$ & 0.28 & 0.28 & 0.47 & 0.95 & 0.8 & 0.9 \\
\hline $\begin{array}{c}\text { Average } \varphi \text { above Oil-Water Contact, } \\
\text { OWC }\end{array}$ & 0.14 & 0.18 & 0.18 & 0.18 & 0.16 & 0.17 \\
\hline $\begin{array}{c}\text { Average } S_{0} \text { above Oil-Water Contact, } \\
\text { OWC }\end{array}$ & 0.43 & 0.46 & 0.42 & 0.63 & 0.5 & 0.27 \\
\hline $\begin{array}{c}{\text { Average } S_{\mathrm{w}} \text { above Oil-Water Contact, }}_{\text {OWC }} \\
\end{array}$ & 0.57 & 0.54 & 0.58 & 0.37 & 0.5 & 0.73 \\
\hline
\end{tabular}

Table3. Relative Permeability and Capillary Pressure Data for Reserveoir Oil and Water

\begin{tabular}{|c|c|c|c|}
\hline Water Saturation, $S_{w}$ & $\begin{array}{c}\text { Relative Permeability of } \\
\text { Water } k_{\mathrm{rw}}\end{array}$ & $\begin{array}{c}\text { Relative Permeability of } \\
\text { Oil } k_{\text {ro }}\end{array}$ & $\mathbf{f}_{\mathrm{w}}\left[\mathrm{k}_{\mathrm{rw}} / \mathrm{k}_{\mathrm{ro}}+\mathrm{k}_{\mathrm{rw}}\right]$ \\
\hline 0.001 & 0.000407 & 0.995707 & 0.000409 \\
\hline 0.01 & 0.005495 & 0.957704 & 0.005705 \\
\hline 0.1 & 0.074131 & 0.635686 & 0.104437 \\
\hline 0.2 & 0.162242 & 0.383078 & 0.297517 \\
\hline 0.3 & 0.256535 & 0.215735 & 0.543195 \\
\hline 0.4 & 0.355081 & 0.111186 & 0.76154 \\
\hline 0.5 & 0.456916 & 0.050766 & 0.900005 \\
\hline 0.6 & 0.56145 & 0.019447 & 0.966522 \\
\hline 0.7 & 0.668284 & 0.005644 & 0.991625 \\
\hline 0.8 & 0.777126 & 0.000987 & 0.998731 \\
\hline 0.9 & 0.887757 & $5.01 \mathrm{E}-05$ & 0.999944 \\
\hline 0.99 & 0.988707 & $2.51 \mathrm{E}-09$ & 1 \\
\hline
\end{tabular}




\section{Appendix B:}

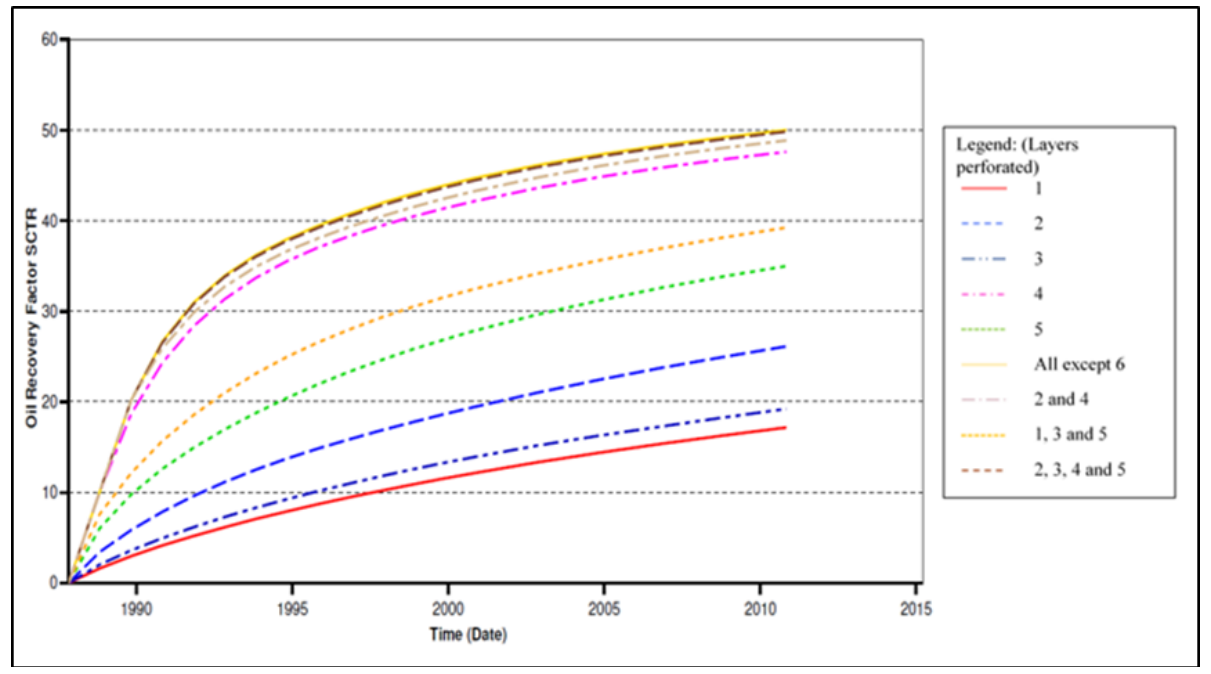

Figure2. Oil Recovery Factor for Various Layers Perforated

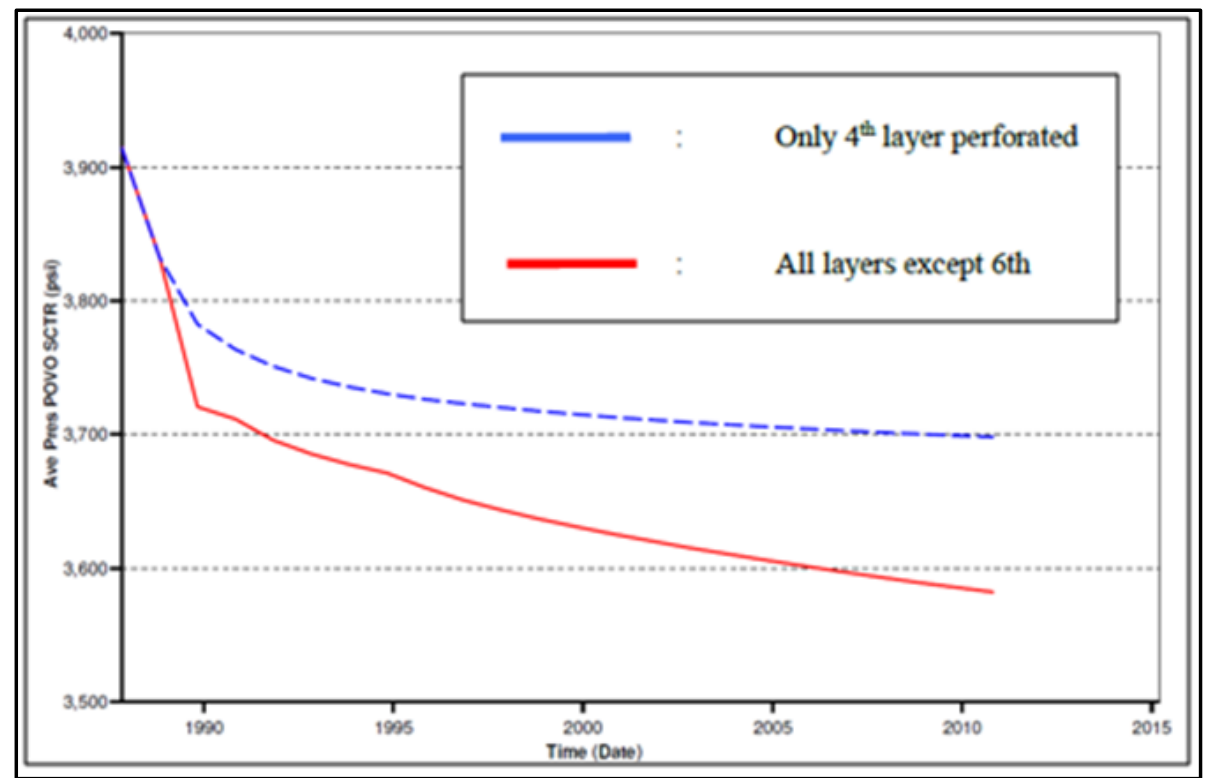

Figure3. Average Reservoir Pressure for Altered Perforation Layers

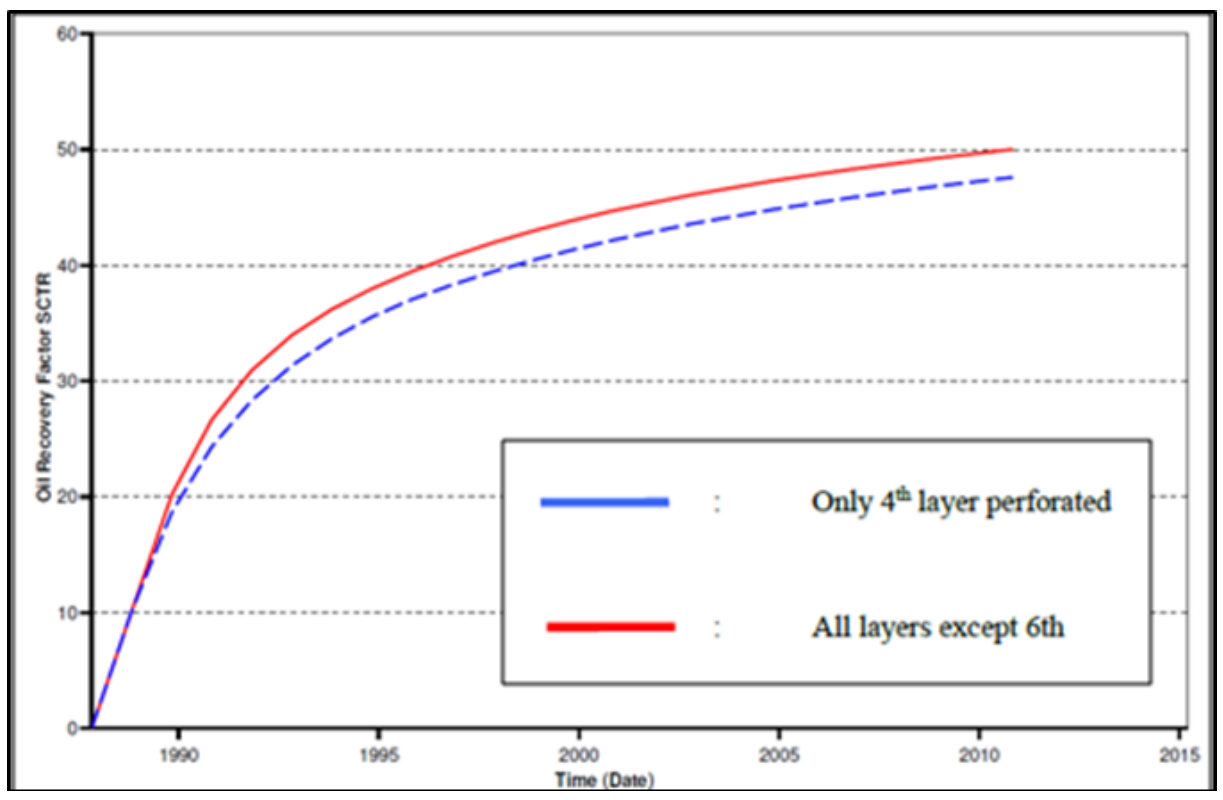

Figure4. Oil Recovery Factor for Altered Perforation Layers 


\section{Appendix C:}

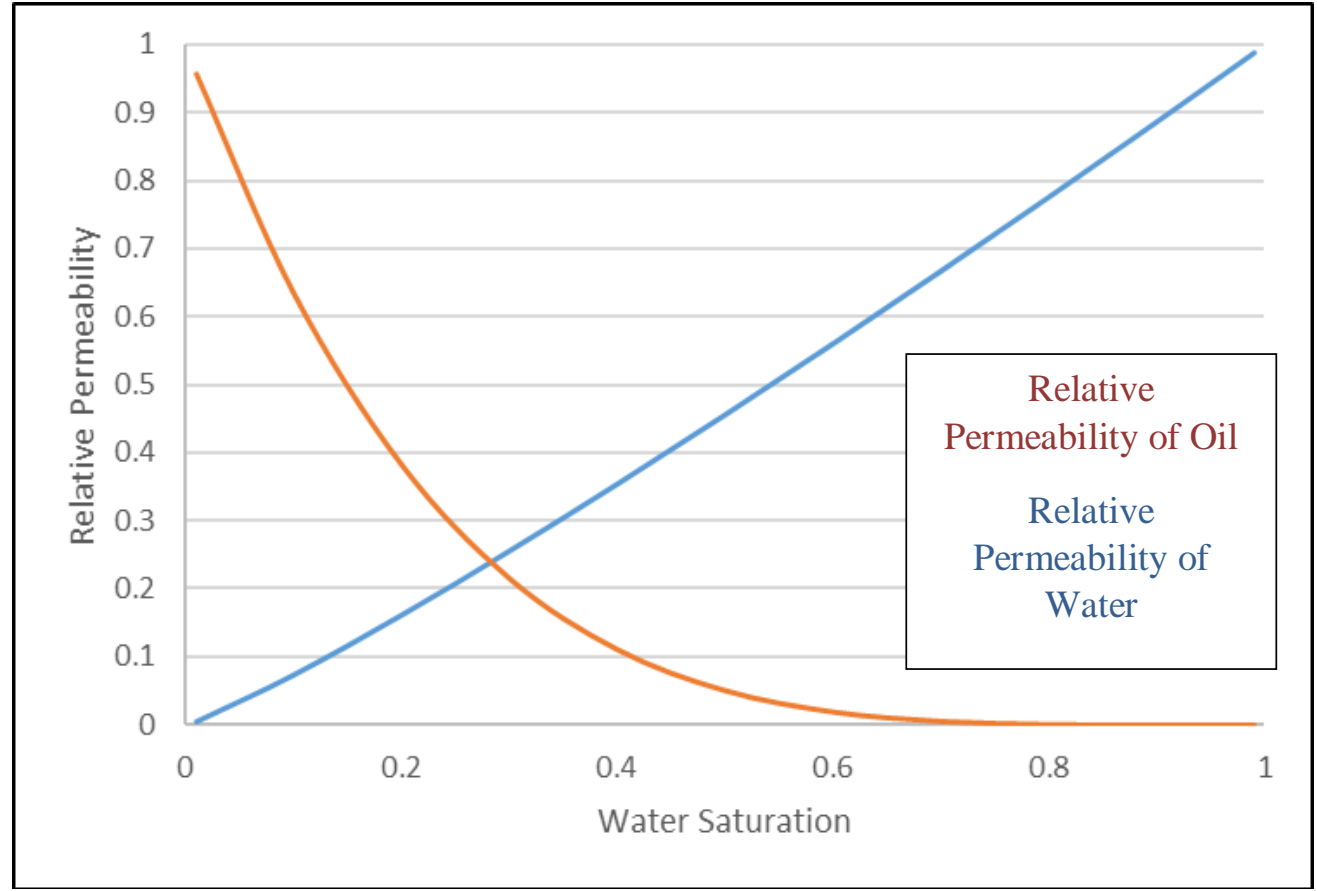

Figure5. Relative Permeabilities of Reservoir Fluid against Water Saturation

$M=\frac{\lambda_{\text {displacing }}}{\lambda_{\text {displaced }}}$

(Equation 1)

$\lambda: \frac{k_{i}}{\mu_{i}}$

$\lambda:$ Mobility

E: Effective permeability

$\mu:$ Viscosity of fluid

$i$ : indicates water, oil or gas



Figure6. Cumulative Oil Production for Water Flooding with Varying Injector Rates 


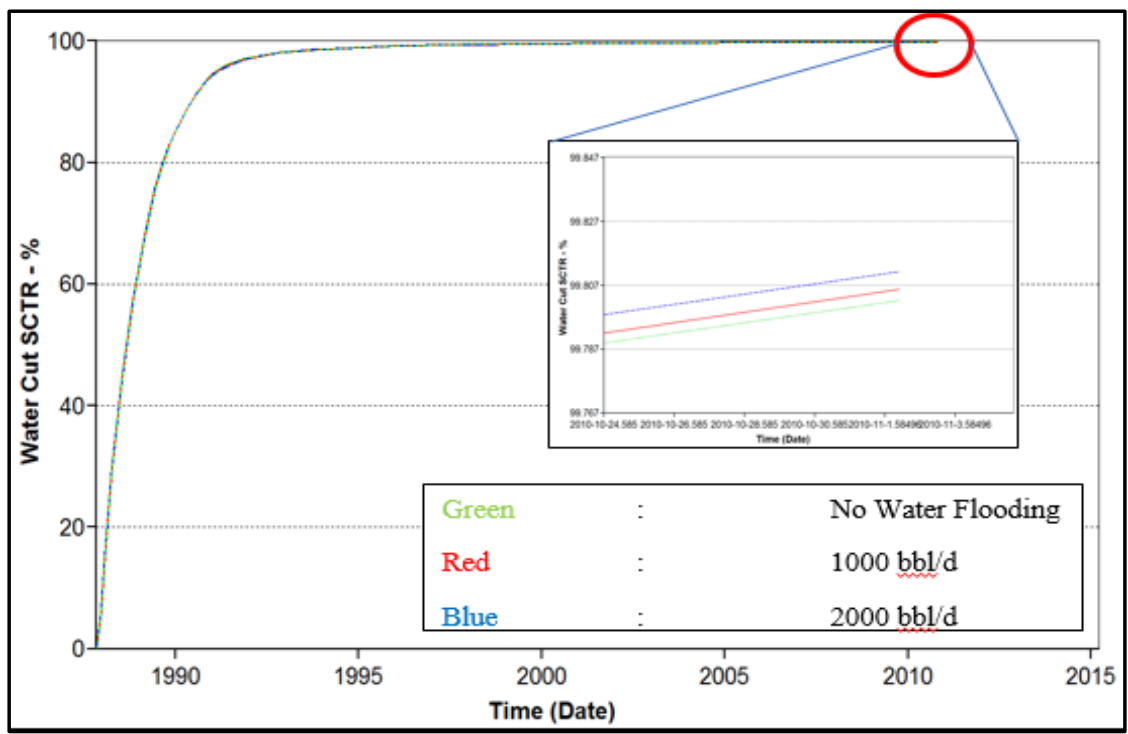

Figure7. Water Cut for Water Flooding with Varying Injector Rates

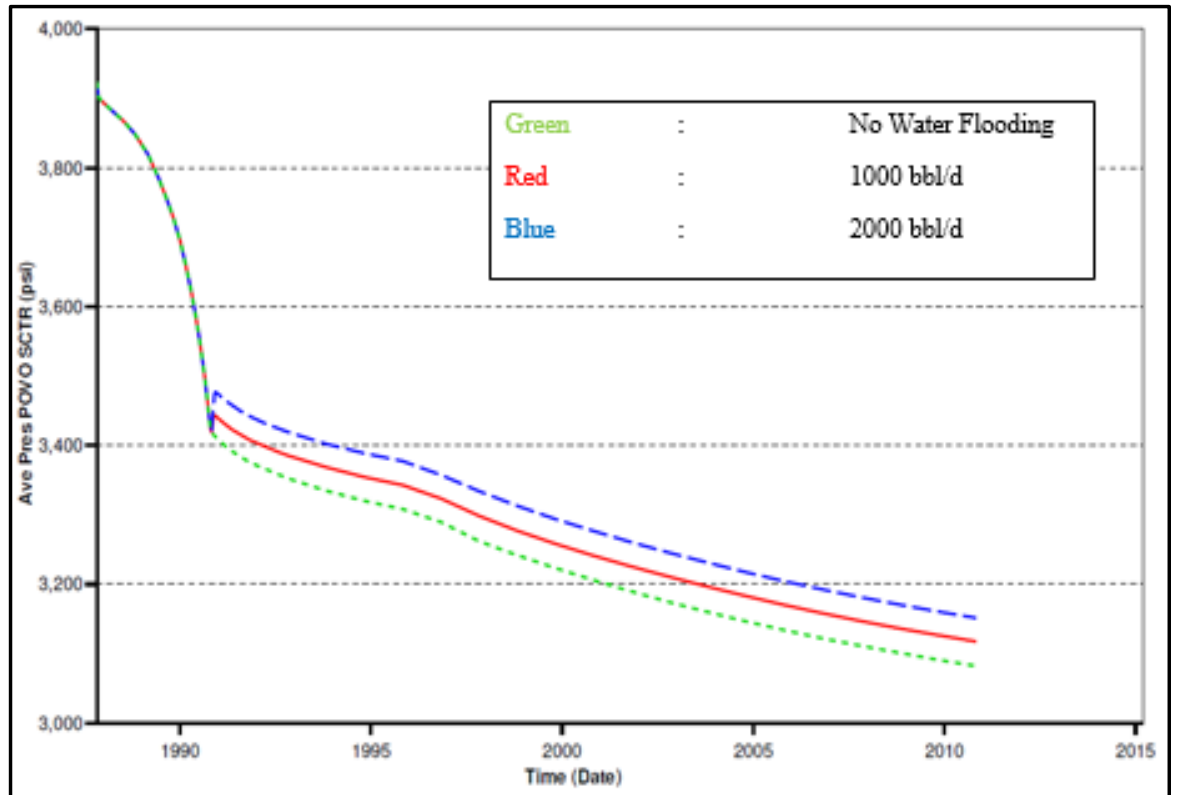

Figure8. Average Rerservoir Pressure for Water Flooding with Varying Injector Rates

\section{Appendix D:}

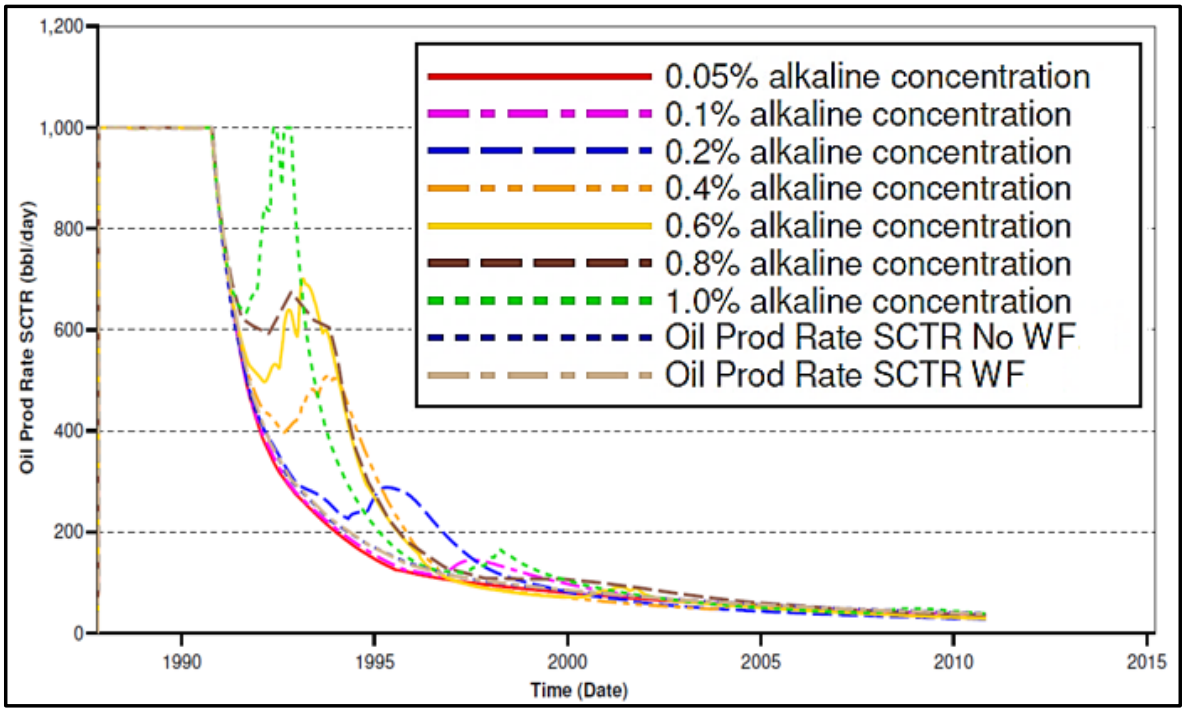

Figure9. Oil Production Rate with Varying Alkaline Concentration 




Figure10. Oil Recovery Factor for Varying Alkaline Flow Rate

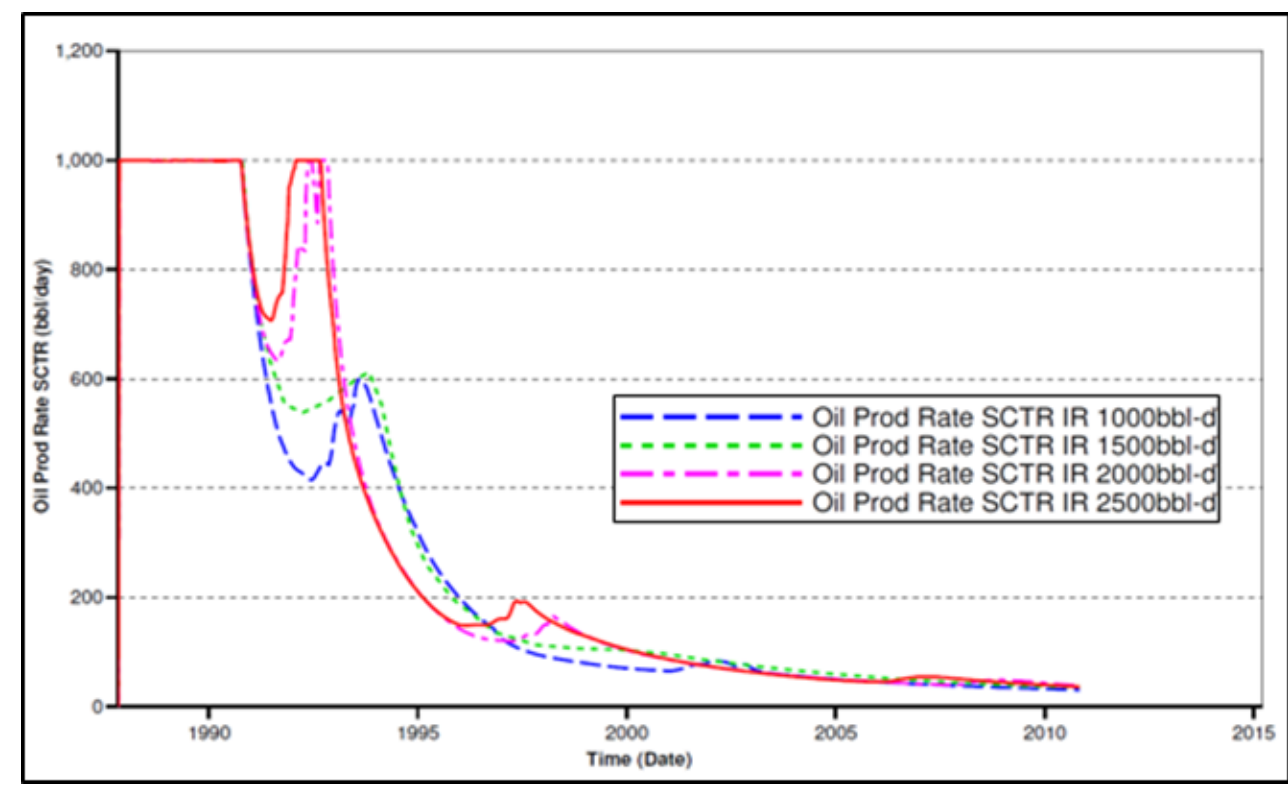

Figure11. Oil Production Rate for Varying Alkaline Flow Rate

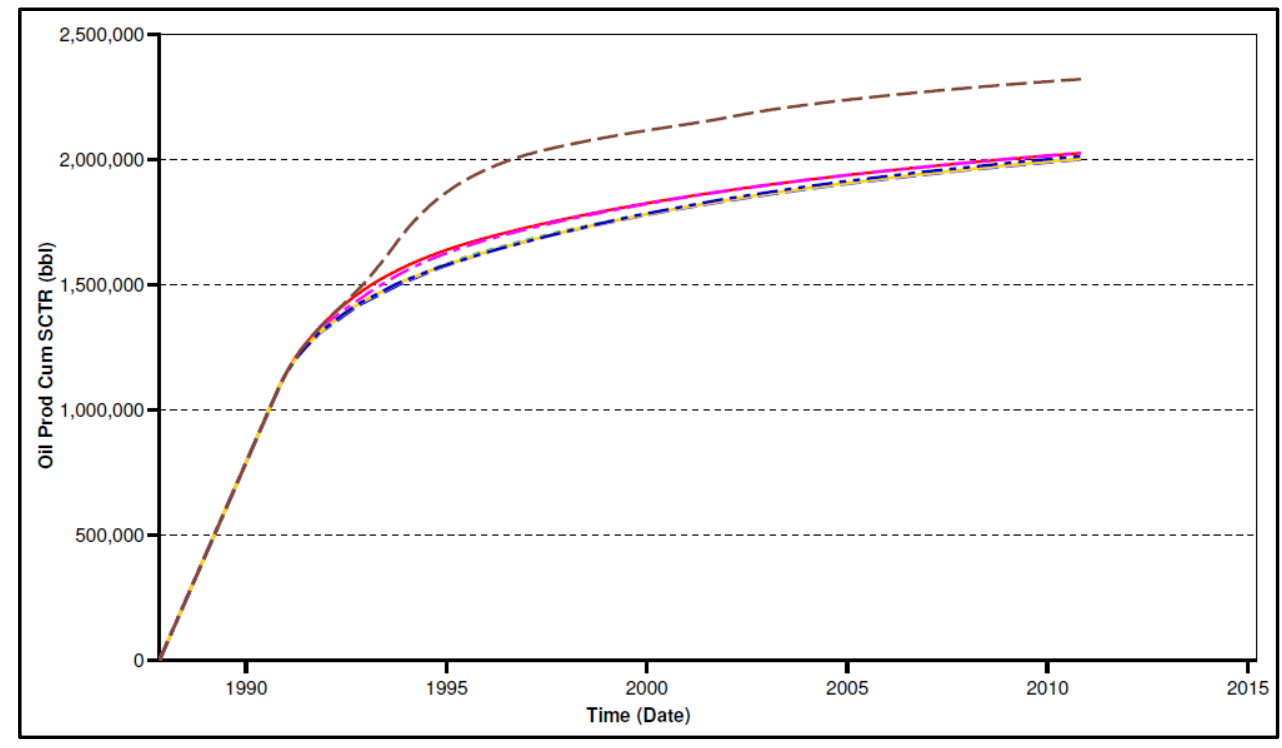

Figure12. Cumulative Oil Produced when Alkaline injected from 1991-1995 


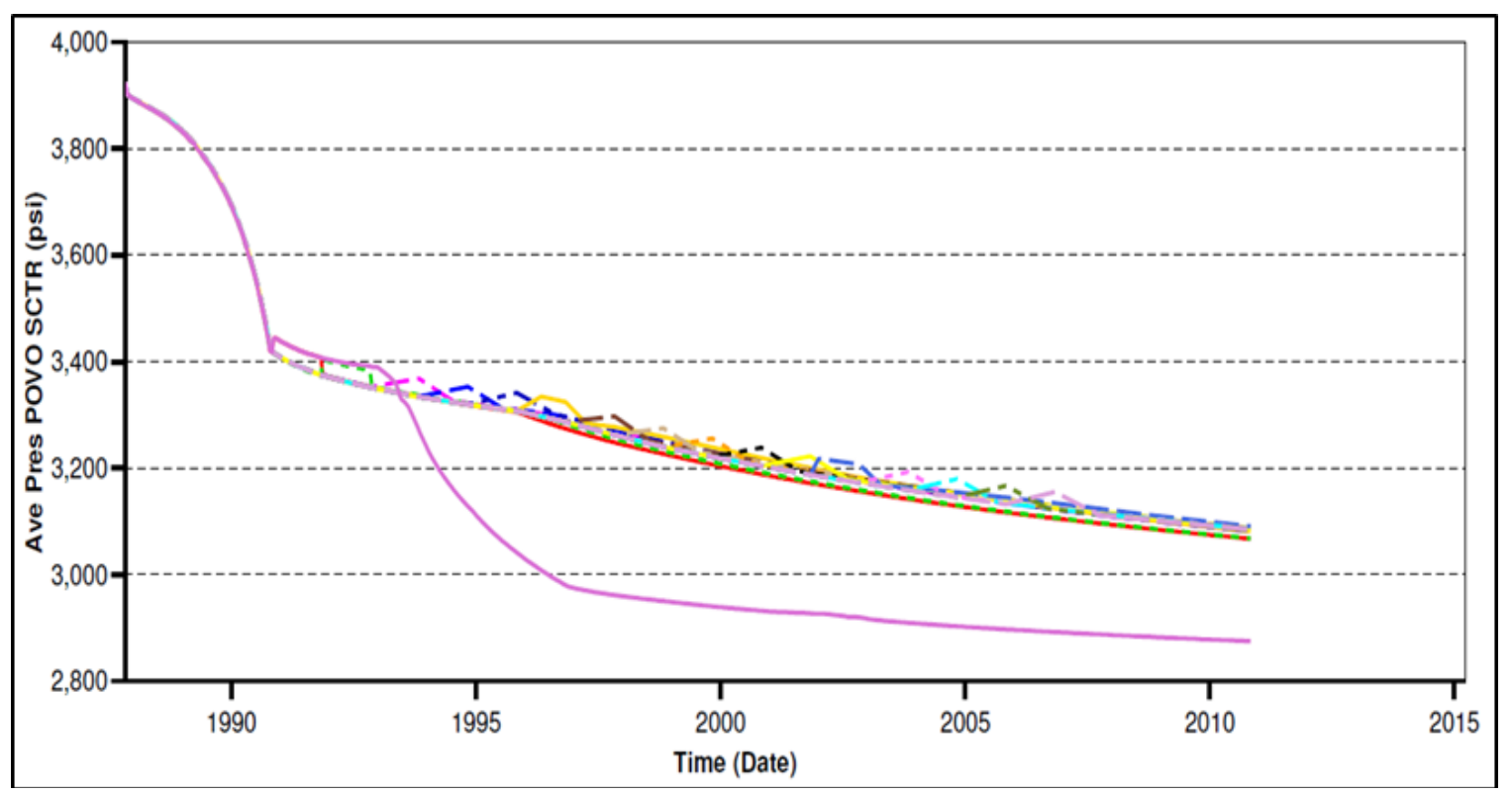

Figure13. Average Reservoir Pressure for Various Flow Period (by individual Years)

\section{REFERENCES}

[1] Abadli, F. (2012). Simulation Study of Enhanced Oil Recovery by ASP (Alkaline, Surfactant and Polymer) Flooding for Norne Field C-Segment. 101. Retrieved from http://www.ipt.ntnu.no/ norne/ wiki/data/media/english/thesis/Maheshwari_Yugal\%20Kishore_Thesis.pdf

[2] Dong, M., Ma, S., \& Liu, Q. (2009). Enhanced heavy oil recovery through interfacial instability: A study of chemical flooding for Brintnell heavy oil. Fuel, 88(6), 1049-1056. http://dx.doi.org/https://doi.org /10.1016/j.fuel.2008.11.014

[3] Keshtkar, S., Sabeti, M., \& Mohammadi, A. H. (2016). Numerical approach for enhanced oil recovery with surfactant flooding. Petroleum, 2(1), 98-107. http://dx.doi.org/http://dx.doi.org/10.1016/j.petlm. 2015.11.002

[4] Maheshwari, Y. K. (2011). A Comparative Simulation Study of Chemical EOR Methodologies (Alkaline, Surfactant and/or Polymer) Applied to Norne Field E-Segment. In F. f. I. O. T. I. f. P. O. A. G. Norges Teknisk-Naturvitenskapelige Universitet (Ed.): (Norges teknisk-naturvitenskapelige universitet, Fakultet for ingeniørvitenskap og teknologi, Institutt for petroleumsteknologi og anvendt geofysikk).

[5] Pei, H., Zhang, G., Ge, J., Jin, L., \& Ma, C. (2013). Potential of alkaline flooding to enhance heavy oil recovery through water-in-oil emulsification. Fuel, 104, 284-293. http://dx.doi.org/https://doi.org/ 10.1016/j.fuel.2012.08.024

[6] Sheng, J. J. (2011). Chapter 10 - Alkaline Flooding Modern Chemical Enhanced Oil Recovery (pp. 389460). Boston: Gulf Professional Publishing. http://dx.doi.org/:http://dx.doi.org/10.1016/B978-1-85617745-0.00010-3

[7] Syed Ata Abbas Naqvi. (2012). Enhanced Oil Recovery of Heavy Oil by Using Thermal and Non-Thermal Methods. Retrieved from https://www.dal.ca/content/dam/dalhousie/pdf/faculty/engineering/peas/ MEng Projects/2012MEngProjects/Syed\%20Ata\%20Abbas\%20Naqvi,\%20Enhanced\%20Oil\%20Recovery\%20o f $\% 20$ Heavy\%20Oil\%20by\%20Using\%20Thermal\%20and\%20Non-Thermal\%20Methods.pdf 
AUTHORS' BIOGRAPHY

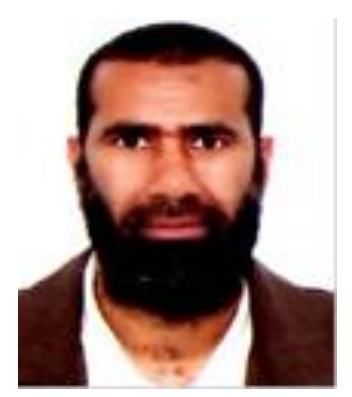

Hisham Khaled Ben Mahmud, has achieved Bachelor, Master and PhD degree in Chemical Engineering from Tripoli University, Sydney University and Curtin University, Australia, respectively. Also I have gained Graduate Diploma in oil and gas from University of Western Australia (UWA). I have expertise in modelling multiphase flow into subsea systems such as pipeline, jumper, riser evaluating pressure drop, and liquid holdup. Also optimize the risk of hydrate blockages into bend pipes. Recently I have involved into upstream research area including reservoir matrix acidizing, experimentally injecting a fluid (acid) into a core sample (sandstone or carbonate) to improve reservoir properties (porosity, permeability) observing wormhole and precipitation reaction. Another area $\mathrm{I}$ involve in is enhanced oil recovery (EOR) in brown oil field using different injecting fluids (CO2, water, polymer, surfactant) or modify production wells in order to improve hydrocarbon fluid recovery by minimizing oil wettability, surface tension and increase contact area.

Citation: Hisham Khaled Ben Mahmud and Yuhashinee Ravichandran (2017). Simulation Study of Enhanced Oil Recovery by Alkaline Flooding In a Mature Oil Field, International Journal of Petroleum and Petrochemical Engineering (IJPPE), 3(4), pp.32-42, DOI: http://dx.doi.org/10.20431/2454-7980.0304003

Copyright: (C) 2017 Hisham Khaled Ben Mahmud and Yuhashinee Ravichandran. This is an open-access article distributed under the terms of the Creative Commons Attribution License, which permits unrestricted use, distribution, and reproduction in any medium, provided the original author and source are credited 